\title{
Comportamento Hidroclimatológico do Estado do Rio Grande do Norte e do Município de Caicó
}

\author{
Rebecca Luna Lucena ${ }^{1}$ iD, Jório Bezerra Cabral Júnior ${ }^{2}$, Ercília Torres Steinke ${ }^{3}$ \\ ${ }^{1}$ Departamento de Geografia, Universidade Federal do Rio Grande do Norte, \\ Caicó, RN, Brasil. \\ ${ }^{2}$ Programa de Pós-Graduação em Ciências Climáticas, \\ Universidade Federal do Rio Grande do Norte, Natal, RN, Brasil. \\ ${ }^{3}$ Programa de Pós-Graduação em Geografia, Universidade de Brasília, Brasília, DF, Brasil.
}

Recebido em 9 de Dezembro de 2017 - Aceito em 18 de Abril de 2018

\begin{abstract}
Resumo
Este artigo teve por objetivo principal analisar o comportamento das chuvas no estado do Rio Grande do Norte (RN) e no município de Caicó no intuito de gerar subsídios à gestão dos recursos hídricos locais, frente a crise hídrica frequentemente vivenciada nesse estado e município, respectivamente. Para tanto, foram utilizados dados pluviométricos (acumulados anuais) de todos os municípios do estado do RN (1963-2013) através do banco de dados da SUDENE e EMPARN e dados de precipitação, evaporação e evapotranspiração de Caicó (1996-2013) do banco de dados do INMET. Para a análise hidroclimatológica foram consultados trabalhos sobre o tema, aplicadas técnicas estatísticas, geoestatísticas, através do método dos Quartis e do Coeficiente de Redistribuição e o Índice de Aridez. Os resultados das análises espaciais foram representados em mapas elaborados no Sistema de Informação Geografica ArcGis 10.0. Os dados mostraram que existe um padrão de distribuição espacial das chuvas no RN onde estas são mais volumosas no litoral leste, seguido pelo oeste potiguar, sendo a região central do estado (que inclui parte do litoral norte) a mais seca. Percebeu-se que a distribuição espacial da precipitação apresentou mesma estrutura tanto em um ano seco como em um ano chuvoso, com os maiores valores no litoral leste, seguido pelo oeste do estado e as áreas serranas do sertão, sendo a região central aquela com os menores valores de chuva. O município de Caicó foi classificado como semiárido e com alta susceptibilidade climática ao processo de desertificação. Observou-se também, para o referido município, que a evaporação supera em muito a precipitação, numa média anual $\sim 5$ vezes, apontando a vulnerabilidade a qual está submetido esse município com relação à escassez de água.
\end{abstract}

Palavras-chave: Rio Grande do Norte, Caicó/RN, precipitação, quartis, índice de aridez.

\section{The Hydroclimatological Behavior of the Brazilian State of Rio Grande do Norte and the Municipality of Caicó}

\begin{abstract}
The aim of this article is to analyze rainfall patterns in the Brazilian state of Rio Grande do Norte and the municipality of Caicó with the objective of providing inputs to support local water resource management in view of the frequent water shortages in the state and the municipality. The data used for this purpose were annual accumulated precipitation data from all the municipalities in the state (1963-2013) from the SUDENE and EMPARN databases, and precipitation, evaporation, and evapotranspiration data on Caicó (1996-2013) from the INMET database. For the hydroclimatological analysis, other research on the subject was consulted, the quartile coefficient of dispersion and redistribution coefficient were used in the statistical and geospatial analyses, and the aridity index was calculated. The results of the spatial analyses were plotted on maps using ArcGis 10.0. The data showed that there is a spatial pattern of rainfall in the state of Rio Grande do Norte, with the highest rainfall occurring along the east coast, followed by the west of the state, while the central part (including part of the north coast) is the driest. It was found that the spatial distribution of precipitation remained the same whether the year was dry or rainy, with the highest values always appearing along the east coast, followed by
\end{abstract}

Autor de correspondência: Rebecca Luna Lucena, rebeccaosvaldo@yahoo.com.br. 
the west of the state and the mountainous areas of the sertão, and finally the central region. Caicó was classified as semi-arid and highly susceptible to desertification. In this municipality, potential evaporation was found to be about five times higher than precipitation on average each year, indicating just how vulnerable it is to water shortage.

Keywords: Rio Grande do Norte, Caicó, Brazil, precipitation, quartiles, aridity index.

\section{Introdução}

As condições hídricas e a disponibilidade de água para consumo humano e animal, dependem, entre vários fatores, da quantidade de água precipitada (chuvas), da quantidade de água evaporada (evaporação e evapotranspiração), assim como da capacidade de absorção de água pelo solo (por meio dos processos de infiltração e percolação). A disponibilidade de água também depende das ações humanas, seja no seu armazenamento, tratamento e utilização, que se feitos de modo inadequado, expõem a população à situação de risco, tanto devido à quantidade, como à qualidade das águas (Rebouças, 2002; Drew, 2005). As águas da chuva, além de serem a fonte original das reservas de águas superficiais (Calasans et al., 2008) utilizadas para suprir as necessidades humanas e animais, são responsáveis pelos processos erosivos, formação dos solos e manutenção da vegetação nativa. Devido a sua grande importância em todos os aspectos acima citados, o estudo do comportamento das chuvas talvez seja um dos mais analisados e difundidos na Climatologia, assim como os estudos sobre a temperatura do ar. Para se estudar as chuvas, técnicas estatísticas e geoestatísticas vêm sendo, desde longa data, utilizadas e aprimoradas, assim como modelos matemáticos e computacionais que buscam cada vez mais o melhoramento das previsões do tempo e do clima (Oliveira, 2010). Assim, esses estudos do comportamento das chuvas, tanto da quantificação quanto da espacialização, bem como da previsão, fornecem informações importantes para a gestão adequada dos recursos hídricos por parte dos governos e da sociedade.

Sabe-se que em regiões subúmidas e semiáridas a questão da água é crucial para o desenvolvimento local e para a manutenção da qualidade de vida, uma vez que nessas áreas tal recurso é mais escasso que nas áreas úmidas e hiperúmidas. No Brasil, a Região Nordeste possui um núcleo de semiaridez há muito tempo conhecido e que já sofreu várias delimitações. Tal região denominada de domínio dos sertões secos (Ab' Saber, 2003), polígono das secas (MMA, 2007), semiárido brasileiro (SUDENE, 2015), é possuidora de um clima que varia desde subúmido à semiárido, marcado pela escassez e irregularidade das chuvas associada às altas taxas de evaporação. No Estado do Rio Grande do Norte tais condições de subumidade e semiaridez são prevalecentes, o que coloca o estado em situação de alerta quando trata-se da disponibilidade hídrica para os múltiplos usos. Como as condições de semiaridez são predominantes no estado, esta condição natural acaba por abranger importantes centros urbanos no interior, como importantes cidades de médio e pequeno porte, a exemplo de Mossoró, Pau dos Ferros, Currais Novos, Macau e Caicó, esta última eleita neste trabalho como a área de interesse por ser uma das maiores e mais influentes cidades do semiárido norte-rio-grandense. Caicó é o mais importante município da microrregião do Seridó Ocidental e é um dos mais importantes de toda a região do Seridó dos estados do Rio Grande do Norte e Paraíba devido ao forte desenvolvimento relativo às atividades comerciais, a pecuária, ao número de estabelecimentos de ensino, hospitais, etc (Faria, 2011).

Quanto as causas da instabilidade das precipitação e da semiaridez nordestina, as explicações baseadas nos sistemas de circulação atmosféricas mais aceitas atualmente estão relacionadas as oscilações da Zona de Convergência Intertropical (ZCIT), agindo conjuntamente "ou não" com as teleconexões, à exemplo do El Niño Oscilação Sul (ENOS), assim como a formação, localização e tempo de duração dos Vórtices Ciclônicos de Altos Níveis (VCANs), (Molion e Bernardo, 2002; Kayano e Andreoli, 2009; Nóbrega e Santiago, 2014; Tedeschi et al., 2014). Tais sistemas explicam a complexidade climática na origem da semiaridez do Nordeste brasileiro.

Sabe-se que um dos principais sistemas geradores de chuva na região semiárida é a ZCIT e que a sua posição mais ao sul no decorrer do ciclo anual coincide com a curta estação chuvosa do Nordeste brasileiro centrada em março-abril (Greischar e Hastenrath, 2000). Na região do Seridó a precipitação é concentrada em uma curta estação úmida, onde os meses mais chuvosos são fevereiro, março e abril, como resultado da influência da ZCIT. Essa curta estação chuvosa compreende vários períodos de chuvas fortes, cada um com duração de alguns dias a uma semana ou mais, separados por períodos de chuva reduzida (Valadão et al., 2015). Nos meses que vão de junho a dezembro as chuvas tem valores quase nulos, marcando o período sazonal da estação seca, mesmo em anos considerados "chuvosos". Esse padrão sazonal da distribuição da chuva no semiárido já é bem conhecido, no entanto a alta variabilidade interanual e espacial das chuvas nesse região ainda não está totalmente compreendida.

Diante deste quadro, neste trabalho, objetivou-se analisar as condições hídricas do estado do Rio Grande do Norte e do município de Caicó através do diagnóstico quantitativo e espacial da distribuição das chuvas, visando fornecer subsídios à gestão adequada das águas, tanto ao nível municipal, quanto estadual. Para tanto, foram consultados trabalhos científicos sobre o tema, utilizados dados de precipitação, evaporação e evapotranspiração, realizadas análises estatísticas e geoestatísticas, como descritas no item 3 . 


\section{O Estado do Rio Grande do Norte e o Município de Caicó}

O estado do Rio Grande do Norte pode ser considerado de clima subúmido e semiárido, visto que segundo as normais climatológicas, $75 \%$ dos municípios apresentam precipitações médias anuais inferiores aos $880 \mathrm{~mm}$. Com distribuição espacialmente irregular das precipitações, pode-se facilmente identificar três domínios climáticos principais: um úmido no Litoral Leste que inclui a mesorregião do Leste potiguar e alguns municípios da mesorregião do Agreste potiguar; um subúmido seco que abrange quase a totalidade da mesorregião Oeste potiguar (sertão), além de alguns municípios da região Central e Agreste; e o domínio de clima semiárido, está presente em quase toda a mesorregião Central potiguar, incluindo alguns poucos municípios do Oeste e Agreste potiguar (IDEMA, 2005; Nunes 2006).

O município de Caicó, objeto de estudo desta pesquisa, é um município de médio porte que está localizado no centro-sul, na mesorregião Central Potiguar do estado do Rio Grande do Norte (Fig. 1). Está no domínio climático semiárido, dentro do polígono das secas, numa área que apresenta alta susceptibilidade ao processo de desertificação. Com uma população total de 62.790 habitantes, estando 57.461 instalados na área urbana do município e 5.248 na zona rural (IBGE, 2010).

No contexto global, o município de Caicó está inserido na zona intertropical do globo, mais próximo da linha do equador que dos trópicos. Essa zona do planeta possui balanço de radiação positivo sendo o fotoperíodo pratica- mente constante, havendo aproximadamente $12 \mathrm{~h}$ de dia e de noite durante todo o ano (Varejão-Silva, 2001). Em se tratando da circulação geral da atmosfera, essa faixa do globo está sujeita à atuação constante dos ventos alísios de sudeste e nordeste, estando sob a ação dos movimentos sazonais da ZCIT e estando praticamente protegida da atuação de massas de ar frias (Nimer, 1979). Assim sendo, em Caicó as estações do ano são melhor identificadas pelos períodos chuvoso e seco do que pelas diferenças sazonais de temperatura (quente e frio), pois há baixa amplitude térmica. Ao nível regional, Caicó está sob o domínio do clima tropical semiárido com regime de chuvas intermitentes, com predomínio de forte insolação diária e anual e altas temperaturas (Nunes, 2006). Trata-se de uma região quente e subúmida/seca ou semiárida. Atuam como sistemas causadores das chuvas, ao nível regional: as Instabilidades Tropicais e os Complexos Convectivos de Mesoescala (geralmente associados à ZCIT); os VCANs e também as Ondas de Leste, sendo esta última responsável por grande parte das chuvas e nebulosidade que atuam no litoral leste do Nordeste brasileiro, porém dificilmente alcançam a depressão sertaneja favorecendo, desse modo, a condição de semiaridez no interior da região. Ao nível local, as chuvas, que são em grande parte de origem convectiva, interagem com os aspectos do solo, relevo e vegetação, promovendo o escoamento superficial rápido e também a rápida recuperação da vegetação.

Devido às condições climáticas existentes no Nordeste semiárido, há, segundo Ab' Saber (2003), uma fraca decomposição das rochas na região, com "malhadas" de

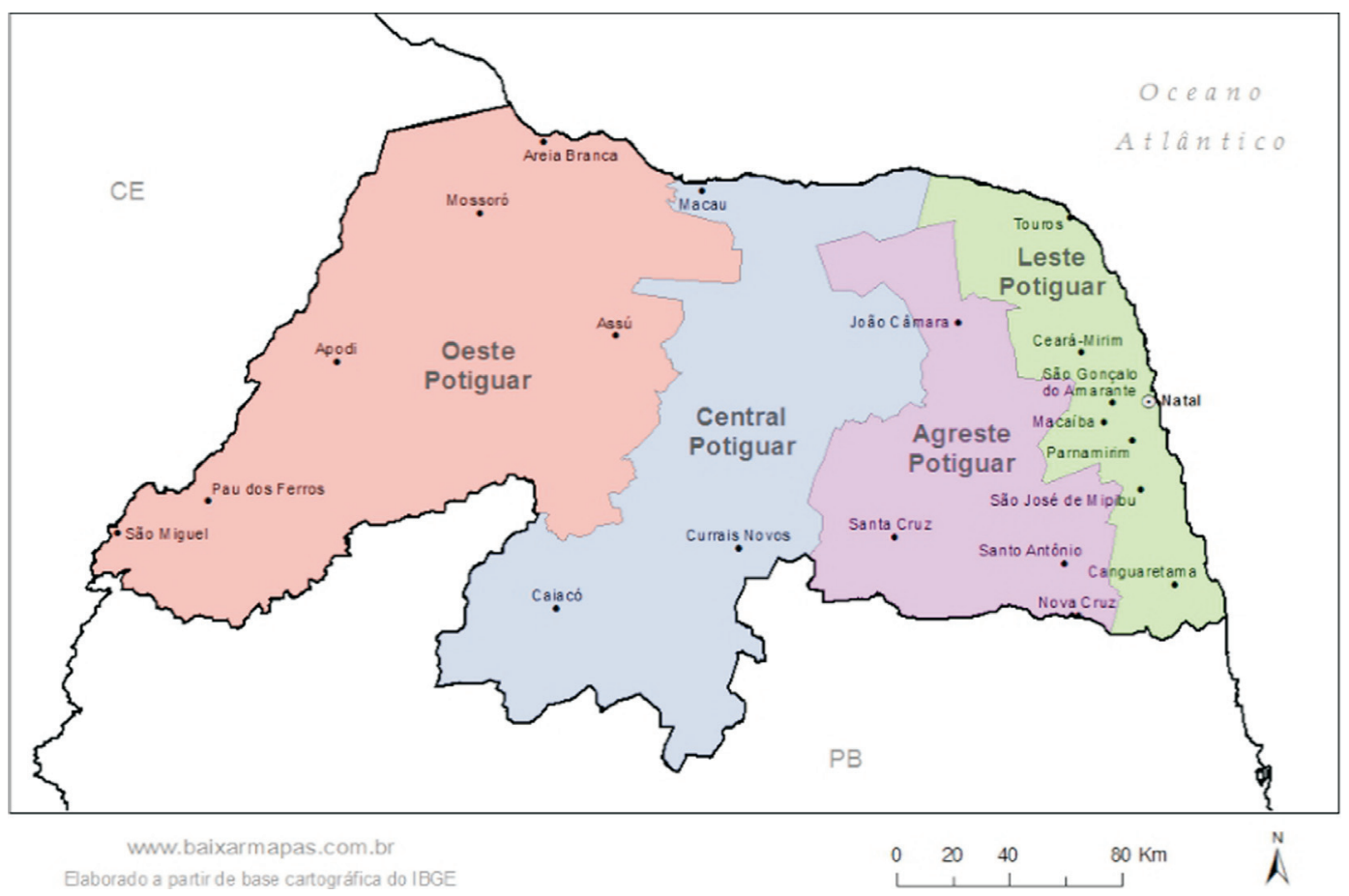

Figura 1 - Mesorregiões Geográficas do estado do Rio Grande do Norte. Fonte: IBGE, 2015. 
chão pedregoso e com muitos afloramentos rochosos. A rede de drenagem é intermitente, relacionada ao ritmo desigual das precipitações. Segundo Ab' Saber (2003), não existe termômetro melhor para delimitar o Nordeste seco do que os extremos da própria vegetação da Caatinga, rica em espécies arbustivo-arbóreas e cactáceas. Tais condições Geográficas expõem a população a vulnerabilidade hídrica que reflete em aspectos sociais, econômicos e culturais importantes. Nesse sentido, justifica-se o estudo das chuvas e do balanço hídrico na região, para que através da identificação dos padrões de precipitação, possa-se melhor gerir os recursos hídricos no estado do Rio Grande do Norte e no município de Caicó e adjacências.

\section{Material e Métodos}

Para se atingir os objetivos deste trabalho, foram realizadas as seguintes etapas metodológicas: Levantamento dos dados de precipitação (acumulado anual) de todos os municípios do estado do Rio Grande do Norte para o período de 1963 a 2013. A escolha de um ano "chuvoso" (2009), um ano "seco" (2013) e a definição de um ano "normal", baseando-se nos acumulados anuais das chuvas observadas no período de 1963 a 2013. A partir da escolha desses anos, foi realizada a análise quantitativa e espacial das chuvas no estado do Rio Grande do Norte através do Coeficiente de Redistribuição e do método dos Quartis. Os resultados das análises espaciais foram representados em mapas elaborados no Sistema de Informação Geográfica ArcGis 10.0.

Para análise exclusiva do município de Caicó, foi realizado o levantamento e a organização de dados acumulados anuais de precipitação, evaporação e evapotranspiração do período de 1996 a 2013; onde aplicaram-se técnicas estatísticas, como probabilidade, tempo de retorno e também o Índice climático de Aridez (IA).

\subsection{Levantamento e organização dos dados de precipitação dos municípios do estado do Rio Grande do Norte}

Para a análise hidroclimatológica utilizaram-se dados de precipitação acumulada de todos os municípios do estado do Rio Grande do Norte. Os mesmos foram adquiridos na Empresa de Pesquisa Agropecuária - EMPARN (EMPARN, 2014), a partir dos postos pluviométricos municipais selecionados pela EMPARN. Para as análises, foram selecionados três anos-padrão: um habitual, um chuvoso e um seco, seguindo a metodologia exposta por Sant' Anna Neto (1990) apud Lucena et al. (2012), onde o ano habitual possua pluviosidade dentro dos desvios médios padrão, variando de $-12,5 \%$ a $12,5 \%$ com relação à média; o ano chuvoso possua precipitações superiores a $25 \%$ da média normal e o ano seco possua índices inferiores a $-25 \%$ da média normal (Lucena et al., 2012).

Para realizar as análises estatística e geoestatística das precipitações, empregou-se a média anual por município para o período de 1963-2013, assim como os valores totais anuais por município de um ano eleito como o chuvoso, nesse caso o ano escolhido foi 2009 , e outro ano eleito como seco, ano de 2013, conforme a metodologia descrita acima. Para o preenchimento das falhas utilizou-se o método de ponderação regional proposto por Tucci (2002).

\subsection{Aplicação do método dos Quartis para o estado do RN}

As separatrizes são medidas baseadas na ordenação dos dados e que dividem um certo número de valores em partes iguais. De acordo com Oliveira et al. (2014) essa técnica vem sendo muito utilizada em análises estatísticas com as vantagens de organizar dados em intervalos regulares sendo assim imunes a eventual assimetria na função de densidade de probabilidades que descrevem um fenômeno aleatório. Os quartis, escolhidos para aplicação neste trabalho, são separatrizes que dividem um conjunto em 4 partes iguais. O Primeiro Quartil ou Quartil Inferior ( $Q i)$, é um valor que delimita os $25 \%$ menores valores de um conjunto de dados, Eq. (1). A Mediana ou Segundo Quartil $(M d)$ separa os $50 \%$ maiores dos $50 \%$ menores valores. O Terceiro Quartil ou Quartil Superior $(Q s)$ é o valor que delimita os 25\% maiores valores (Reis, 2015), Eq. (2).

$$
Q i=\frac{(n+1)}{4}
$$

em que $Q i$ é o Quartil inferior e $n$ é o número total de elementos da amostra.

$$
Q s=\frac{3(n+1)}{4}
$$

em que $Q s$ é o quartil superior e $n$ é o número total de elementos da amostra.

Logo, nesse estudo, o Primeiro Quartil ou Quartil Inferior ( $Q i)$, é um valor que delimita os $25 \%$ menores valores de precipitação contemplando os primeiros 42 municípios (posição de 1 à 42). A Mediana ou Segundo Quartil (Md) representa 84 municípios (posição de 43 à 125), e o Terceiro Quartil ou Quartil Superior $(Q s)$ é o valor que delimita os $25 \%$ maiores valores de precipitação representado por 42 municípios (posição de 126 à 167).

\subsection{Aplicação do Coeficiente de Redistribuição para o estado do RN}

O coeficiente de redistribuição é uma técnica geoestatística que se preocupa com a distribuição do fenômeno no espaço, ou seja, procura identificar padrões de concentração ou dispersão de uma atividade em determinado período. Portanto, está associado a uma atividade $A k$ e compara a distribuição espacial dessa atividade em dois períodos diferentes (período $t$ e período $s$ ) Eq. (3). $R k=1$, quando a atividade $A k$ sofre completa redistribuição espacial entre os períodos $t$ e $s . R k=0$ quando a atividade $A k$ 
em nada se altera sobre a estrutura espacial nos períodos $t \mathrm{e}$ $s$ (Souza e Alves, 2011).

$$
R_{k}^{(t, s)}=\frac{1}{2} \sum_{r=1}^{n}\left|P_{r k}^{(t)}-P_{r k}^{(s)}\right|
$$

em que $R$ é o Coeficiente de redistribuição, $k$ é a atividade em questão, $n$ é o número de espaços geográficos, $t$ é um período $t, s$ é o período de tempo $s$ e $r k$ é o percentual da atividade $k$ no espaço $r$.

Esse coeficiente é importante na observação do comportamento espacial de um fenômeno, nesse caso, a distribuição da chuva no estado do Rio Grande do Norte. A resposta que se pretende alcançar, utilizando esse método, é se existe diferença na distribuição espacial das chuvas no estado do Rio Grande do Norte, quando se compara a um ano considerado "seco" a um ano considerado "chuvoso".

\subsection{Coleta e organização dos dados de precipitação, evaporação e evapotranspiração do município de Caicó/RN}

Os dados anuais de precipitação e evaporação, acumulados, analisados para o município de Caicó, referem-se ao período de 18 anos, de 1996 a 2013, cujos dados foram utilizados para analisar a probabilidade e o tempo de retorno.

A evapotranspiração acumulada anual (período de 2003 a 2013), foi disponibilizada pelo Instituto Nacional de Meteorologia (INMET), para em seguida calcular o Índice de Aridez. Esses dados advêm da estação climatológica principal do Seridó (Caicó), e os mesmos também estão disponíveis no Banco de Dados Meteorológicos para Ensino e Pesquisa (BDMEP), disponível no site do INMET (INMET, 2015). Os dados referem-se aos valores totais anuais das três variáveis mencionadas: precipitação, evaporação e evapotranspiração potencial.

\subsection{Probabilidade, tempo de retorno e índice de aridez para o município de Caicó}

"Considerando o lançamento de um dado, o conjunto de todos os casos possíveis de ocorrer é o conjunto das possibilidades" (Francisco, 1995, p.45). Para se chegar aos valores de probabilidade, deve-se distribuir os dados em classes e expressar a relação entre o número de vezes que determinado fenômeno ocorreu e o número total de eventos observados (Galvani, 2005), Eq. (4).

$$
P=f r=\frac{n a}{n}
$$

sendo $P$ a probabilidade, $f r$ a frequência relativa, $n a$ o número de vezes que determinado evento aconteceu e $n$ o número total de elementos da série.

Enquanto o Tempo de Retorno expressa um intervalo de tempo estimado para que determinado evento ocorra. É definido como o inverso da probabilidade (Galvani, 2005), Eq. (5).

$$
T=\frac{1}{P}=\frac{1}{f r}
$$

sendo $T$ o tempo de retorno e $P$ a probabilidade e $f r$ frequência relativa.

Em 1992, a ONU, por meio do Programa das Nações Unidas para o Meio Ambiente (PNUMA), estabeleceu um Índice de Aridez (ÍA), aceito internacionalmente, que se expressa pelo quociente da divisão entre precipitação média anual dividida pela evapotranspiração potencial (Eq. (6)), com a seguinte gradação: valores superiores a 0,65 significariam ausência de aridez; entre 0,65 e 0,51, corresponderiam ao subúmido; $0,50-0,21$ ao semiárido; 0,20-0,05 ao árido e inferiores a 0,05 ao hiperárido." (Conti, 2008, p. 43-44).

$$
I A=\frac{P}{P E T}
$$

em que $I A$ é o índice de aridez, $P$ é a precipitação e $P E T$ é a evapotranspiração potencial.

De acordo com Pacheco et al. (2006) e Reboita et al. (2016), o governo brasileiro adotou um padrão de susceptibilidade à desertificação que varia entre áreas consideradas de alto, moderado e baixo riscos à desertificação, utilizando-se para esta classificação o Índice de Aridez ÍA, como exposto na Tabela 1.

Os dados referentes a evapotranspiração potencial, adquiridos através do Banco de Dados Meteorológicos para Ensino e Pesquisa - BDMEP do INMET, foram obtidos através do método proposto por Thornthwaite e Mather (1955).

\section{Resultados e Discussão}

\subsection{Análise hidroclimatológica do estado do Rio Grande do Norte}

Para fins de identificar e localizar os eventos climáticos, pode-se consultar o mapa das mesorregiões do estado do Rio Grande do Norte (Fig. 1 - item 2), que apesar de nesta delimitação, o IBGE não trazer apenas os aspectos físicos, mas sobretudo aspectos socioeconômicos, como segue "a divisão regional do Brasil em mesorregiões, partindo de determinações mais amplas a nível conjuntural, buscou identificar áreas individualizadas em cada uma das

Tabela 1 - Intervalos do Índice de Aridez com as classes climáticas e as respectivas categorias de susceptibilidade à desertificação. Fonte: Barros, 2010.

\begin{tabular}{lll}
\hline $\begin{array}{l}\text { Valores para a fórmula } \\
\text { P/PET }\end{array}$ & Classes climáticas & $\begin{array}{l}\text { Susceptibilidade à } \\
\text { desertificação }\end{array}$ \\
\hline $0,05<0,20$ & Árido & Muito alta \\
$0,21<0,50$ & Semiárido & Alta \\
$0,51<0,65$ & Subúmido seco & Moderada \\
$>0,65$ & Subúmido úmido & Não susceptível \\
\hline
\end{tabular}


Unidades Federadas, tomadas como universo de análise e definiu as mesorregiões com base nas seguintes dimensões: o processo social como determinante, o quadro natural como condicionante e a rede de comunicação e de lugares como elemento da articulação espacial" (IBGE, $2015 \mathrm{~s} / \mathrm{p}$ ), o mesmo se torna indispensável para a assimilação geográfica da análise climática que será feita a seguir.

Analisando o comportamento das chuvas a partir do método dos quartis pode-se perceber que em um ano considerado "normal", $25 \%$ dos municípios do Rio Grande do Norte apresentam valores médios anuais inferiores aos $603,3 \mathrm{~mm}$. Estes estão localizados na região central - leste do estado, abrangendo parte da mesorregião do Agreste Potiguar e da mesorregião Central Potiguar, como exposto na Fig. 2, representados pela cor amarela. A mediana, ou seja $50 \%$ dos municípios apresentaram chuvas anuais entre 603,3 e 870 mm, estão localizados em quase toda mesorregião do Oeste Potiguar, além de alguns pontos da região Central e também do Agreste Potiguar (cor verde). Por último, o terceiro quartil mostrou que $25 \%$ dos municípios apresentam valores superiores aos $870 \mathrm{~mm}$ de chuvas anuais, estes localizados no Litoral Leste, mesorregião Leste Potiguar e em poucos municípios do Agreste e Oeste potiguar. O ano considerado "normal" representa a média anual de precipitação para o período de 1963 a 2013, como explicado no item 3.

Para um ano considerado "chuvoso" $25 \%$ dos municípios apresentaram precipitação anual inferior aos $941,9 \mathrm{~mm}, 50 \%$ precipitações anuais entre 941,9 e $1300 \mathrm{~mm}$ e outros $25 \%$ apresentaram precipitações anuais superiores aos $1300 \mathrm{~mm}$. Quanto ao arranjo espacial, notase que, em um ano chuvoso, o litoral Leste apresenta maior homogeneidade, enquanto que as regiões do Agreste, Central e Oeste Potiguar tiveram um comportamento mais heterogêneo (Fig. 3). A mesorregião Oeste de certo modo apresentou totais pluviométricos dentro da mediana, entre 941,9 e 1300, num ano chuvoso e ainda partes da região Central e Agreste apresentaram os totais mais baixos $\left(1^{\circ}\right.$ quartil, em amarelo).

Analisando o comportamento das chuvas a partir do método dos quartis para um ano considerado "seco", observamos que $25 \%$ dos municípios do Rio Grande do Norte apresentam valores anuais inferiores aos $349,5 \mathrm{~mm}$. 50\% dos municípios apresentaram chuvas anuais entre 349,5 e $784,4 \mathrm{~mm}$. O terceiro quartil mostrou que $25 \%$ dos municípios apresentam valores superiores aos 784,4 $\mathrm{mm}$ de chuvas anuais, estes localizados principalmente no litoral leste, e em alguns municípios do Oeste potiguar, principalmente em áreas serranas (Fig. 4). Quanto à distribuição espacial dos totais de precipitação, percebe-se que o padrão espacial de um ano "seco" muito se assemelha ao padrão espacial de um ano "normal", exibindo nitidamente totais pluviométricos mais elevados no litoral leste, seguidos pelo Oeste potiguar e mostrando uma área mais seca na região central leste, que inclui a mesorregião Central potiguar e poucos municípios do Agreste potiguar.

Aplicando-se o Coeficiente de Redistribuição, obteve-se como resultado o valor de 0,18 , o que implica dizer que a chuva pouco se alterou sobre a estrutura espacial do estado do Rio Grande do Norte entre um ano chuvoso (2009) e seco (2013). Nota-se mais uma vez, que o Litoral Leste é detentor das maiores cotas pluviométricas, seguido pelo Oeste potiguar, e a Região Central e partes do

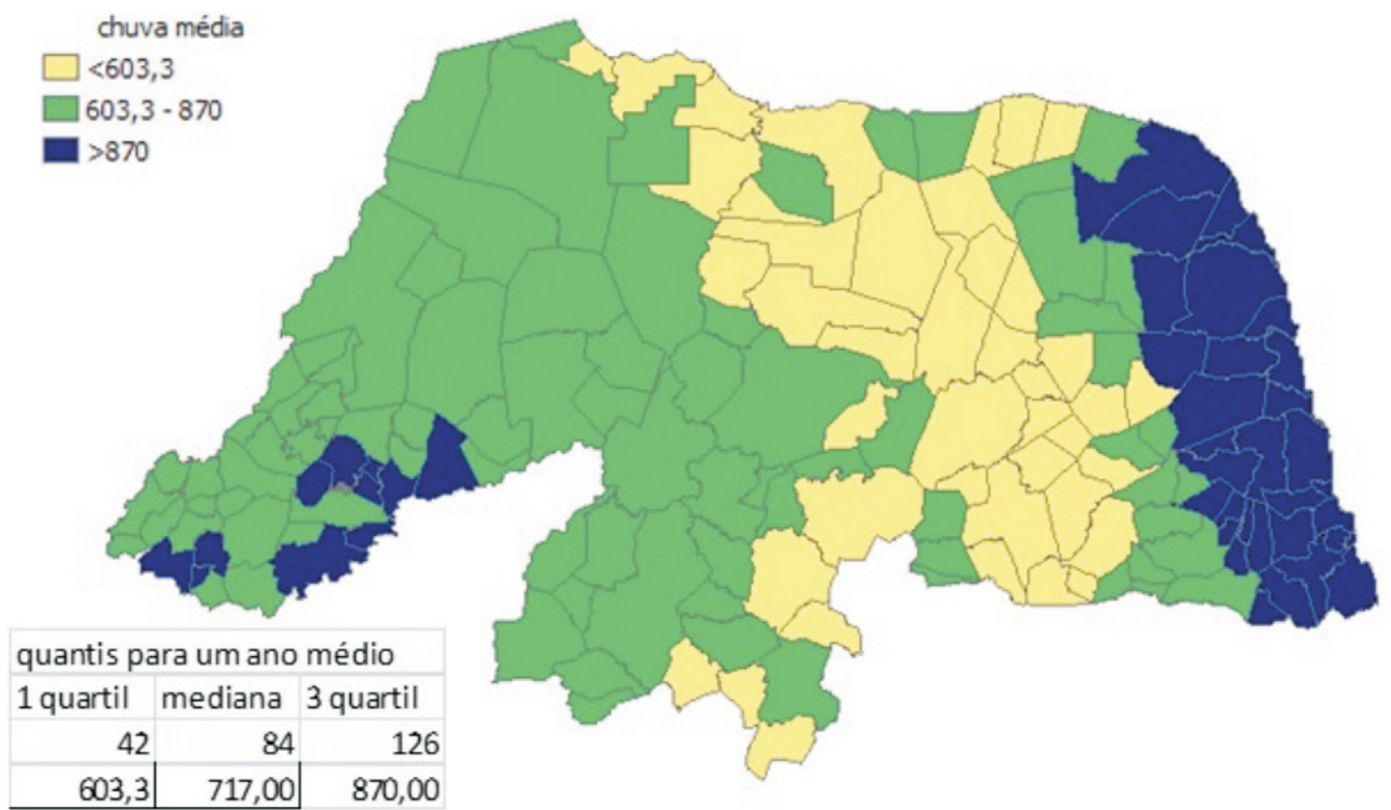

Figura 2 - Distribuição espacial do acumulado anual de precipitação para um ano "normal” no estado do Rio Grande do Norte, período: 1963 a 2013. Fonte: dados da pesquisa. 


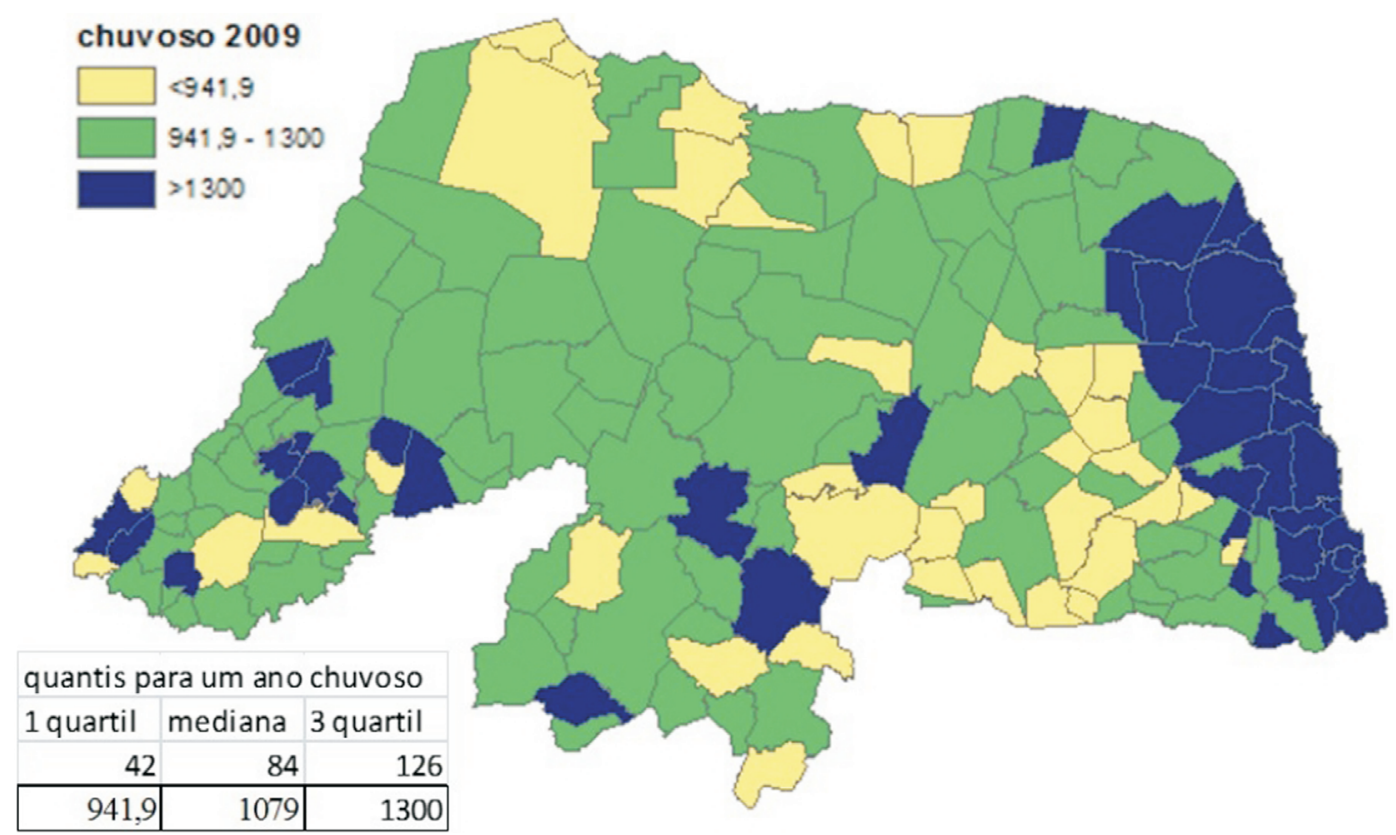

Figura 3 - Distribuição espacial do acumulado anual de precipitação para um ano “chuvoso - 2009" no estado do Rio Grande do Norte, período: 1963 a 2013. Fonte: dados da pesquisa.

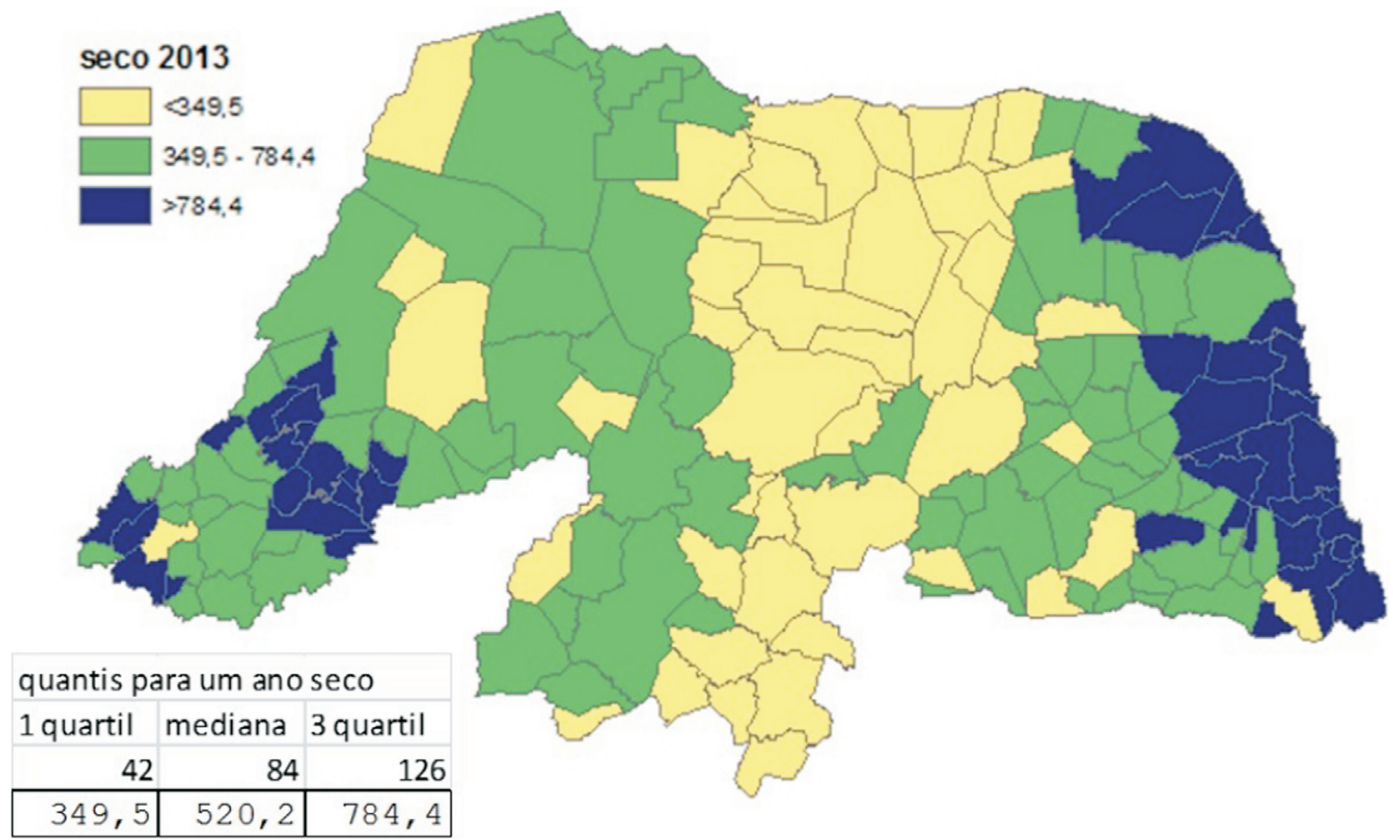

Figura 4 - Distribuição espacial do acumulado anual de precipitação para um ano “seco - 2013” no estado do Rio Grande do Norte, período: 1963 a 2013. Fonte: dados da pesquisa.

Agreste possuidoras das menores cotas pluviométricas (ver Fig. 5).

É importante ressaltar que no trabalho em questão, a análise aborda exclusivamente anos específicos, 2009 e 2013, ao observar que estes foram bastante anômalos, considerando-se o comportamento médio entre 1963 a 2013, podendo haver variação na distribuição espacial das chuvas no $\mathrm{RN}$, em anos que apresentem totais pluviométricos semelhantes.

\subsection{Análise hidroclimatológica do município de Caicó/RN}

Analisando os dados de precipitação e evaporação potencial do município de Caicó de 1996 a 2013, aplicando medidas de tendência central e de dispersão, chegou-se aos 


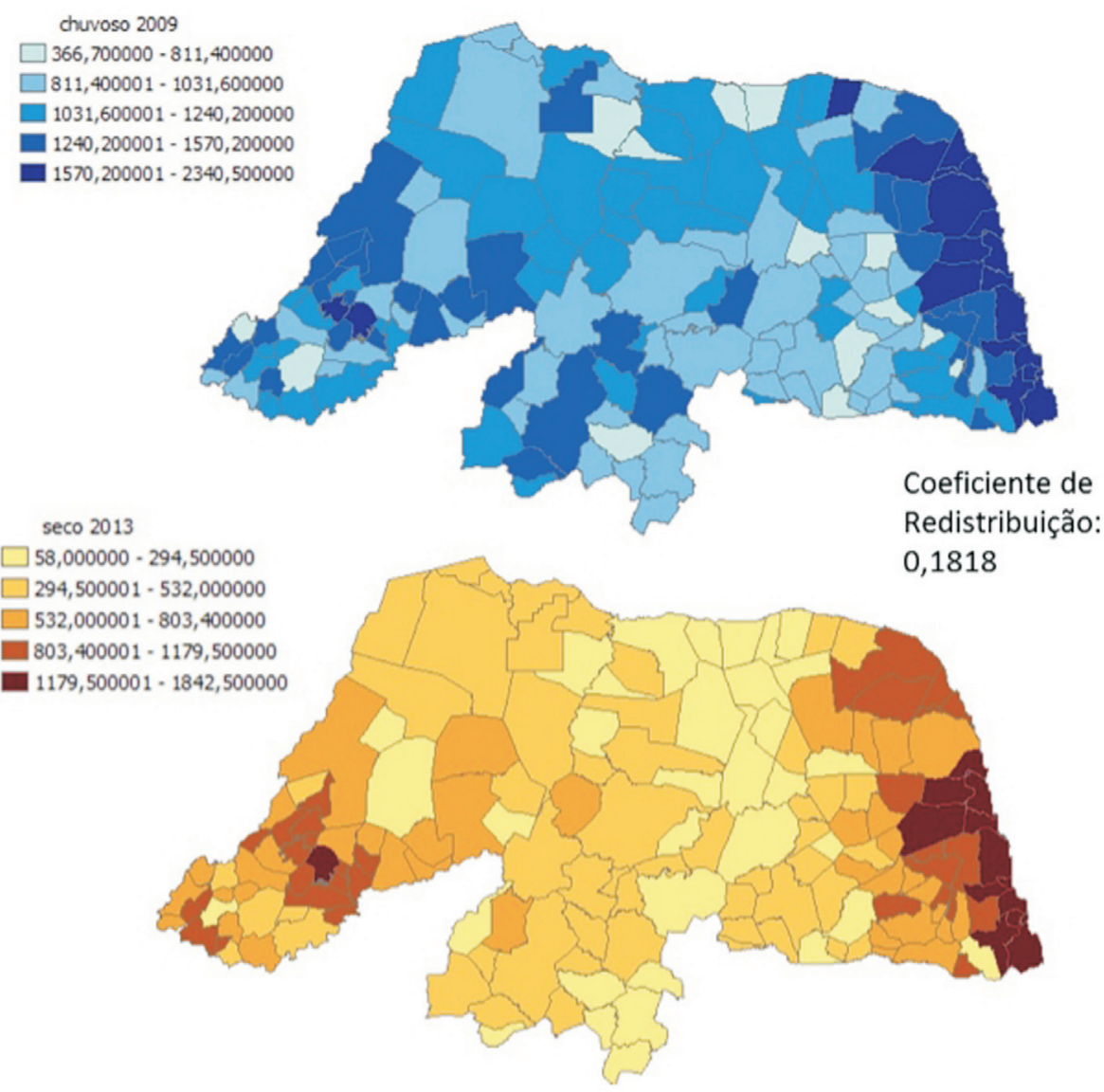

Figura 5 - Intervalos de precipitação acumulada anual para municípios do estado do Rio Grande do Norte em um ano chuvoso (2009) e outro seco (2013), com o respectivo coeficiente de redistribuição, período: 1963 a 2013. Fonte: dados da pesquisa.

seguintes resultados: as médias de precipitação e evaporação anual foram de 638,1 e 3098,3 mm, respectivamente. Tais valores mostram que, em média, anualmente a quantidade de água evaporada é 5 vezes maior que a quantidade de água precipitada em Caicó. Esta informação, por si só, mostra que existe um déficit de água na superfície que pode gerar problemas com relação à demanda natural e socioeconômica (Lucena e Steinke, 2014), (Tabela 2).

Os valores Máximo e Mínimo expressam simplesmente o maior e menor valor da amostra (série de dados), indicando a amplitude. A Amplitude total é a diferença en-

Tabela 2 - Estatísticas da Precipitação e Evaporação Potencial para Caicó-RN, período: 1996 a 2013. Fonte: Lucena e Steinke, 2014.

\begin{tabular}{lcc}
\hline Caicó/RN (período 1996 - 2013) & $\begin{array}{c}\text { Precipitação } \\
(\mathrm{mm})\end{array}$ & $\begin{array}{c}\text { Evaporação } \\
(\mathrm{mm})\end{array}$ \\
\hline Média aritmética & 638,1 & 3098,3 \\
Valor máximo & 1191,2 & 3655,3 \\
Valor mínimo & 174,6 & 2630,9 \\
Amplitude total & 1016,6 & 1024,4 \\
Desvio padrão da população & 274,6 & 280 \\
Coeficiente de variação & $43 \%$ & $9 \%$ \\
\hline
\end{tabular}

tre o V. Max e o V. Min do conjunto de dados. Quanto maior for a amplitude total, maior é a variabilidade dos valores (Reboita, 2005). Para a precipitação e evaporação no município de Caicó os V. Max e V.Min foram: 1191,2 e $174,6 \mathrm{~mm}$ e 3655,3 e $2630,9 \mathrm{~mm}$ respectivamente. Em Caicó as Amplitudes Totais para precipitação e evaporação foram de 1016,6 mm e 1024,4 $\mathrm{mm}$, respectivamente. Os valores de amplitude total das duas variáveis foram muito semelhantes, no entanto, convém lembrar que os V Max e $\mathrm{V}$. Min são bem distintos para as duas variáveis, o que nos mostra que mesmo com amplitude semelhante, a variável evaporação predomina sobre a precipitação.

Para precipitação e evaporação os valores do Desvio Padrão foram de 274,6 e $280 \mathrm{~mm}$, respectivamente. Estes valores foram bem próximos, mas o Coeficiente de Variação, por sua vez mostra que na realidade não é tão parecido assim. Apesar dos dados de precipitação e evaporação de Caicó com relação ao Desvio Padrão terem sido bem semelhantes, o CV mostrou que os dados de chuva apresentaram uma maior heterogeneidade do que os dados de evaporação. Esta variabilidade foi quase 5 vezes maior para precipitação, com CV de $43 \%$ e de $9 \%$ para evaporação (Tabela 2). Este resultado é muito importante, pois mostra que além da chuva ser inferior à evaporação em termos de 
quantidade, ela também é mais variável no tempo (Lucena e Steinke, 2014).

Os conjuntos de dados de precipitação e evaporação foram agrupados em cinco intervalos de classes e os resultados mostraram que para precipitação, existe uma maior probabilidade de ocorrência (28\%) de precipitações entre 581 e $784 \mathrm{~mm}$, ou seja, para os valores mais próximos à média. Por outro lado há uma menor probabilidade (11\%) para eventos de chuva em que o total anual supere 988,0 $\mathrm{mm}$. Para os dados de evaporação os resultados foram os seguintes: maior probabilidade (28\%) da evaporação anual para valores entre 3245 e $3450 \mathrm{~mm}$ e menor probabilidade (11\%) para valores de 3451 a $2655 \mathrm{~mm}$ Para os valores de evaporação, há uma maior probabilidade de ocorrência para valores que se encontram 1 classe acima da que está a média, o que significa que a evaporação tende a ser maior que a média, agravando ainda mais a situação hídrica local. Ressalta-se que a evaporação potencial ter sido maior que a precipitação, não significa necessariamente, que evapore mais água do que precipita. Essa condição ocorre divido a elevada disponibilidade energética da atmosfera no referido município, ou seja, há uma demanda de evaporar 3098,3 mm (em média) caso haja água disponível o suficiente na superfície.

O tempo de retorno ou de recorrência é o tempo (geralmente em anos) estimado para ocorrer um determinado evento dentro de um intervalo de classe, definido assim como o inverso da probabilidade, que para Caicó-RN foi de 3,7 anos para os valores de precipitação próximos da média, entre 581,26-784,58 mm, e de 9 anos para precipitações superiores aos $900 \mathrm{~mm}$. Logo, o tempo de retorno para que ocorra uma chuva superior a $900 \mathrm{~mm}$, valor de um ano considerado "chuvoso", é de aproximadamente 9 anos, conforme pode ser observado na Tabela 3.

\section{3. Índice de Aridez (IA)}

Para distinguir as diferentes regiões do globo de acordo com os tipos climáticos, foram e vêm sendo elaborados vários modelos de classificação climática. A depender do propósito, estes modelos se utilizam de diferentes variáveis meteorológicas. Algumas classificações levam em consideração as massas de ar e ventos, outras o balanço de radiação, outras ainda o grau de umidade (Torres e Macha- do, 2011). O IA é uma classificação climática que enfoca a disponibilidade hídrica de uma região assim como pode inferir a susceptibilidade ao processo de desertificação, como descrito adiante.

Para Caicó aplicou-se o IA por ano e a média para todos os anos. A série considerada foi de 10 anos, por faltarem dados de evapotranspiração potencial anteriores ao ano de 2003 (Tabela 4). Na Tabela 4, observa-se que a média do IA para o município foi de 0,41 , classificando o clima de Caicó como semiárido. Na série analisada foram registrados 1 ano sem aridez (2009) e 1 ano árido (2012), com taxas de 0,68 e 0,11 respectivamente.

Quanto a susceptibilidade à desertificação, verificou-se que Caicó está altamente susceptível a este processo, se levarmos em conta as condições climáticas atuantes, obtendo um valor médio de 0,41 no índice de Aridez, como pode ser visto na Tabela 4 e na Fig. 6.

No ano de 2012, o índice de Aridez de 0,11 classificou o município de Caicó como árido e com muito alta susceptibilidade ao processo de desertificação. Segundo Marengo et al. (2017) as condições de seca que começaram a se intensificar em todo Nordeste semiárido em 2012 estiveram ligadas a uma anomalia no Oceano Atlântico tropical que favoreceu uma posição anômala da ZCIT ao norte, contribuindo para anomalias negativas de precipitação no NEB. Ainda segundo esses autores, as condições do evento La Nina (fraca) em 2013 não foram suficientes para compensar as condições de seca estabelecidas anos antes. Somando-se aos aspectos climáticos o delgado manto intempérico e a vegetação esparsa da Caatinga, pode-se detectar um problema geográfico maior que interfere de sobremaneira na quantidade dos recursos hídricos superficiais e subterrâneos no semiárido nordestino (Zanella, 2014).

Já no ano de 2009, o resultado do Índice de Aridez 0,68, classificou Caicó como sem aridez e sem susceptibilidade à desertificação. Cabe destacar que com relação aos eventos ENOS, apesar de 2009 ter sido um ano neutro, apresentando condições de El Niño só a partir do mês de junho, 2008 foi um ano de ocorrência de forte La Niña e de chuvas acima de média em quase todo Nordeste brasileiro. Da mesma forma que o primeiro semestre de 2009, especificamente o mês de fevereiro, teve uma forte atuação do

Tabela 3 - Intervalos de classes e os respectivos períodos de retorno da precipitação e evaporação potencial, para o município de Caicó-RN (período de 1996 - 2013). Fonte: Lucena e Steinke, 2014.

\begin{tabular}{lcccc}
\hline & Precipitação & & \multicolumn{2}{c}{ Evaporação } \\
\cline { 1 - 2 } Inter. de classe & Tempo de retorno & Inter. de classe & Tempo de retorno \\
\hline $174,6-377,92$ & 4,5 & 6,2 & $2630,9-2835,78$ & 4,5 \\
$377,93-581,25$ & 3,7 & $2835,79-3040,67$ & 6,2 \\
$581,26-784,58$ & 4,5 & $3040,68-3245,56$ & 4,5 \\
$784,60-987,91$ & 9,0 & $3245,57-3450,45$ & 3,7 \\
$987,92-1191,24$ & & $3450,46-3655,34$ & 9,0 \\
\hline
\end{tabular}


Tabela 4 - Índice de Aridez e Susceptibilidade à Desertificação para o município de Caicó-RN para os dez últimos anos (período 2003 - 2013 ). Fonte: Lucena e Steinke, 2014.

\begin{tabular}{lccccc}
\hline Caicó período 2003-2013* & Precipitação & Evapotrans. potencial & Índice de aridez & Classificação climática & Susceptibil. desertificação \\
\hline 2003 & 589,8 & 1760 & 0,335114 & Semiárido & Alta \\
2004 & 797,7 & 1745 & 0,457135 & Semiárido & Alta \\
2006 & 760,8 & 1787 & 0,425844 & Semiárido & Alta \\
2007 & 548,4 & 1776 & 0,308784 & Semiárido & Alta \\
2008 & 875,2 & 1763 & 0,496427 & Semiárido & Alta \\
2009 & 1191,2 & 1747 & 0,681855 & Subúmido úmido & Não Susceptível \\
2010 & 700,6 & 1746 & 0,40126 & Semiárido & Alta \\
2011 & 969,6 & 1716 & 0,565035 & Subúmido seco & Moderada \\
2012 & 200,2 & 1773 & 0,112916 & Árido & Muito alta \\
2013 & 597,6 & 1766 & 0,338392 & Semiárido & Alta \\
Média & 723,11 & 1757,85 & 0,411359 & Semiárido & Alta \\
\hline
\end{tabular}

*exceto 2005 por falta de dados.

\section{Susceptibilidade à Desertificação no município de Caicó}

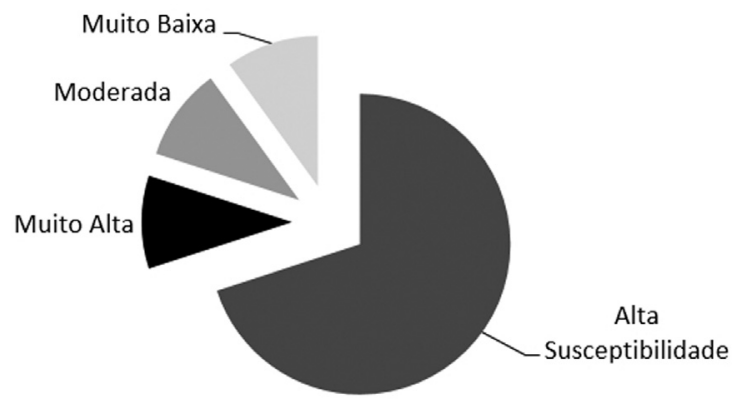

Figura 6 - Proporção de anos susceptíveis à desertificação no município de Caicó para o período de 2003 à 2013. Fonte: dados da pesquisa.

VCAN e um posicionamento da ZCIT ao sul de sua climatologia, o que favoreceu a ocorrência de chuvas acima da média histórica, principalmente no estado do Rio Grande do Norte, como documentado no Boletim de Informações Climáticas - INFOCLIMA (INMET, 2009).

Os resultados aqui apresentados só confirmam a vulnerabilidade a que está submetido o município de Caicó, dentro desse contexto macro da semiaridez, com relação à falta de água, numa perspectiva de crescimento urbano para os próximos anos. Medidas eficazes para armazenamento, distribuição e reuso de água e preservação e conservação da Caatinga existente devem ser tratadas com prioridade pelo governo e sociedade.

\section{Conclusões}

A partir dos resultados, pôde-se observar que o estado do Rio Grande do Norte possui, de um modo geral, precipitações relativamente baixas, visto que $75 \%$ dos municípios apresentam precipitações médias anuais inferiores aos $871 \mathrm{~mm}$.
Por meio do método dos quartis, observou-se que em um ano considerado chuvoso, $75 \%$ dos municípios apresentaram precipitação superior aos $941,9 \mathrm{~mm}$, sendo que $25 \%$ apresentou totais anuais superiores aos $1300 \mathrm{~mm}$, estes localizados principalmente no litoral leste do RN. Para um ano seco, $75 \%$ dos municípios apresentaram precipitações inferiores aos $784,4 \mathrm{~mm}$, sendo que o primeiro quartil, que corresponde a $25 \%$ dos municípios, apresentou precipitações inferiores aos $349,5 \mathrm{~mm}$, estando estes concentrados, sobretudo, na mesorregião Central potiguar. Tanto em anos considerados normais, assim como em anos chuvosos e secos, a distribuição espacial das chuvas mostrou pouca alteração, como confirmado pelo Coeficiente de Redistribuição com resultado de 0,18 , com os maiores totais pluviométricos no litoral leste (mesorregião Leste potiguar), assim como em algumas áreas serranas do extremo oeste do estado (mesorregião Oeste potiguar). A região mais seca do RN abarca a parte central - leste do estado chegando até o litoral Norte (mesorregião Central potiguar) e partes do Agreste potiguar.

O município de Caicó, localizado na mesorregião Central potiguar, apresentou, no período de cem anos, maior frequência de chuvas entre $471 \mathrm{~mm}$ e $653 \mathrm{~mm}$ anuais. Viu-se também que a evaporação supera em muito a precipitação, numa média anual de 5 vezes mais. Mesmo no ano mais chuvoso da série analisada (2009), a evaporação demonstrou ter um potencial de pelo menos 3 vezes maior que a precipitação. O Coeficiente de Variação mostrou que a chuva apresentou uma maior variabilidade interanual que a evaporação, sendo o $\mathrm{CV}$ de $43 \%$, para a chuva e de $9 \%$ para a evaporação. Este resultado é muito importante, pois mostra que, além da chuva ter sido inferior à evaporação em termos de quantidade, ela também é mais variável no tempo. Quanto à probabilidade, o intervalo de classe de chuva que contém a média é o que apresenta maior possibilidade de ocorrência enquanto os melhores índices de chuva, que seriam superiores aos $900 \mathrm{~mm}$, apresentaram a menor pro- 
babilidade de ocorrência. Já o tempo de recorrência de um evento anual de chuva foi menor para os valores de precipitação próximos da média, entre 581,26-784,58 $(\sim 3,7$ anos $)$ e maior para precipitações superiores aos $900 \mathrm{~mm}$ ( 9 anos).

Os resultados da aplicação do ÍA mostraram que o município de Caicó se enquadra na condição de clima "semiárido" com "alta susceptibilidade climática à desertificação". Tais resultados só confirmam a vulnerabilidade a que está submetido o município de Caicó com relação à falta de água, numa perspectiva de crescimento populacional para os próximos anos.

Muitos municípios do estado do Rio Grande do Norte, principalmente aqueles localizados na mesorregião Central potiguar, apresentam características climáticas semelhantes e até mais hostis que o município de Caicó, com baixas taxas de precipitação e forte variabilidade temporal e espacial das mesmas. Assim sendo, medidas eficazes para armazenar a água e proteger a vegetação Caatinga devem ser tratadas com prioridade pelo governo e sociedade. Métodos que armazenem a água e que evitem sua perda por evaporação como construção de barragens subterrâneas, cisternas, construção de reservatórios profundos (em relevo adequado) e a dragagem dos reservatórios já existentes, podem diminuir a perda de água por evaporação. Medidas de proteção do solo são também tão relevantes quanto as de armazenamento de água. A construção de renques e barramentos ajuda a segurar os solos e também o conteúdo de umidade presentes neles, favorecendo o melhor desenvolvimento da vegetação Caatinga e consequentemente maior retenção de água no sistema, sendo estas medidas que devem ser colocadas como a ordem do dia no estado do Rio Grande do Norte.

\section{Agradecimentos}

Ao INMET (Instituto Nacional de Meteorologia/Brasil) por disponibilizar os dados meteorológicos utilizados nesta pesquisa

\section{Referências}

AB'SABER, A.N. Caatingas: O domínio dos sertões secos. In: Os domínios de natureza no Brasil: potencialidades paisagísticas. $1^{\mathrm{a}}$ Edição. São Paulo: Ateliê Editorial, 2003.

BARROS, $\mathrm{K}$ de O. Índice de aridez como indicador da susceptibilidade à desertificação na mesorregião norte de Minas. Monografia (Geografia). Universidade Federal de Viçosa, Minas Gerais, 2010. 89p.

CALASANS, N.A.R.; LEVY, M, do C.T.; MOREAU, M. Interrelações entre clima e vazão. In: Schiavetti, A. \& Camargo, A. F. M. Conceitos de Bacias hidrográficas: teorias e aplicações. Ilhéus/BA: Editus, 2008.

CONTI, J.B. O conceito de Desertificação. CLIMEP - Climatologia e Estudos da Paisagem, v. 3, n. 2, p. 39-52, 2008.

DREW, D. Água. In: DREW, D. Processos interativos homem -

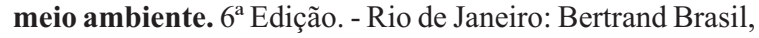
2005. 206 p.
EMPARN - Empresa de Pesquisa Agropecuária do RN - EMPARN Gerência de Meteorologia. Climatologia Rio Grande do Norte. Disponível em: http://189.124.201.150/climaRN/medias_historicas_munici pios_RN.htm, Acesso em: 10/10/2014.

FARIA, C.E. Os eventos geográficos e a expansão urbana de Caicó. Natal: Editora do IFRN, 2011.

FRANCISCO, W. de. Estatística básica: síntese da teoria, exercícios propostos e resolvidos. $2^{\mathrm{a}}$ Edição. Piracicaba: Editora Unimep, 1995.

GALVANI, E. Métodos e técnicas de quantificação em Geografia. In: VENTURI, L. A. B (Org). Praticando Geografia: Técnicas de Campo e Laboratório. $1^{\text {a }}$ Edição. São Paulo: Oficina de Textos, v. 1, 2005. 239 p.

GREISCHAR, L.; HASTENRATH, S. The Rainy Seasons of the 1990s in Northeast Brazil: Real-Time Forecasts and Verification. Journal of Climate, v. 13, p. 3821-3826, 2000.

IBGE (Instituto Brasileiro de Geografia e Estatística), 2010. IBGE Estados. Disponível em: http://www.ibge.gov.br/estadosat/perfil.php?sigla=rn, Acesso em 12/10/2013.

IBGE (Instituto Brasileiro de Geografia e Estatística), 2015. Divisão regional. Disponível em: http:/www.ibge.gov.br/home/geociencias/geografia/default_div_int.shtm?c = 1, Acesso em 08/11/2015.

IDEMA - Instituto de Desenvolvimento Econômico e do Meio Ambiente do Rio Grande do Norte). Perfil do Estado do Rio Grande do Norte. Secretaria de Estado do Planejamento e das Finanças do Rio Grande do Norte: Natal, 2005.

INMET - Instituto Nacional de Meteorologia. Boletim de Informações Climáticas - INFOCLIMA. Brasília: INMET. Ano 16, 20 de março de 2009, Número 03. Disponível em: http://www.inmet.gov.br/por-

tal/arq/clima/prognostico-climatico-trimestral/PC0903_b.p df. Acesso em 12/12/2009.

INMET - Instituto Nacional de Meteorologia. BDMEP. Disponível em: http://www.inmet.gov.br/portal/index.php?r=bdmep/bdmep. Acesso em 20/12/2015.

KAYANO, M.T.; ANDREOLI, R.V. Clima da região Nordeste do Brasil. In: Tempo e clima no Brasil. Cavalcanti, I. F. de A. (Org). São Paulo: Oficina de Textos, 2009.

LUCENA, J.A.; SOUZA, B.I.; MOURA, M. de O.; LIMA, J. de O. Análise da variabilidade da precipitação pluviométrica como subsídio para o planejamento agrícola em Caicó/RN. Revista brasileira de Climatologia, v. 10, p. 121 - 135, 2012.

LUCENA, R.L.; STEINKE, E.T. Diagnóstico climático para o município de Caicó/RN com ênfase à disponibilidade de água no sistema-superfície-atmosfera. Anais.. In: X Simpósio Brasileiro de Climatologia Geográfica, 2014, Curitiba. Anais do X Simpósio Brasileiro de Climatologia Geográfica. Curitiba: ABClima, 2014. p. 1577-1587.

MARENGO, J.A.; ALVES, L.M.; ALVALA, R.C.S.; CUNHA, A.P.; BRITO, S.; MORAES, O.L.L. Climatic characteristics of the 2010-2016 drought in the semiarid Northeast Brazil region. Anais da Academia Brasileira de Ciências, p. 1-13, 2017.

MMA - Ministério do Meio Ambiente. SANTANA, M. O (Org). Atlas das áreas susceptíveis à desertificação do Brasil. Brasília: Ed: MMA - Ministério do Meio Ambiente, 2007. 
MOLION, L.C.B.; BERNARDO, S.O. Uma revisão da dinâmica das chuvas no Nordeste brasileiro. Revista Brasileira de Meteorologia, v. 17, n. 1, p. 1-10, 2002.

NIMER, E. Circulação atmosférica do Nordeste e suas consequências: o fenômeno das secas. In: Climatologia do Brasil. Rio de janeiro: IBGE, 1979.

NÓBREGA, R.S.; SANTIAGO, G.A.C.F. Tendência de temperatura na superfície do mar nos oceanos Atlântico e Pacífico e variabilidade de precipitação em Pernambuco. Mercator, v. 13, n. 1, p. 107-118, 2014.

NUNES, E. Geografia física do Rio Grande do Norte. Natal: Imagem Gráfica, 2006.

OLIVEIRA, J.C.F. de (Org). Atmosfera e sociedade: a ação da atmosfera sobre os seres vivos e a qualidade de vida humana. v. 1. Maceió: EDUFAL, 2010.

OLIVEIRA, P.T.; SILVA, C.M.S.; LIMA, K.C. Linear trend of occurrence and intensity of heavy rainfall events on Northeast Brazil. Atmospheric Science Letters. n. 15, p. 172$177,2014$.

PACHECO, A. da P.; FREIRE, N.C.F.; BORGES, U. da N. A transdisciplinaridade da Desertificação. Geografia (Londrina), v. 15, n. 1, p. 5-34, 2006.

REBOITA, M.S.; RODRIGUES, M.; ARMANDO, R.P.; FREITAS, C.; MARTINS, D.; MILLER, G. Causas da Semiaridez do sertão nordestino. Revista Brasileira de Climatologia, v. 19, p. 254-277, 2016.

REBOITA, M.S. Introdução à Estatística Aplicada à Climatologia: Parte I Estatística Descritiva. Projeto PAE. São Paulo, 2005.

REBOUÇAS, A. de C. (Org). Águas doces no Brasil: capital ecológico, uso e conservação. São Paulo: Escrituras Editora, 2002. 703p.
REIS, M.M. Quartis. Disponível em: http://www.inf.ufsc.br/ marcelo.menezes.reis/AED05.pdf, Acesso em 12/12/2015.

SOUZA, C.C.G. de; ALVES, L.R.. A especialização e a reestruturação produtiva das atividades econômicas entre as mesorregiões do Brasil entre 2000 a 2009. Informe Gepec, Toledo, v. 15, n. Especial, p. 145-161, 2011.

SUDENE - Superintendência de Desenvolvimento do Nordeste. Região Nordeste. Disponível em: http://www.sudene.gov.br/acesso-a-informacao/institucion al/area-de-atuacao-da-sudene/regiao-nordeste. Acesso em 09/03/2015.

TEDESCHI, R.G.; GRIMM, A.M.; CAVALCANTI, I.F.A. Influence of Central and East ENSO on extreme events of precipitation in South America during austral spring and summer. International Journal of Climatology, v. 35, p. 20452064, 2014

TORRES, F.T.P.; MACHADO, P. J. de O. Introdução à Climatologia. São Paulo: Cengage Learning, 2011.

TRIOLA, M.F. Introdução à Estatística. $7^{\mathrm{a}}$ Edição. Rio de Janeiro: LTC, 1998.

TUCCI, C. E. M. Hidrologia: Ciência e Aplicação. $3^{\text {a }}$ Edição. Porto Alegre: Ed. da Universidade, 2002.

VALADÃO, C.E.A.; LUCIO, P.S.; CHAVES, R.R.; CARVALHO, L.M.V. MJO Modulation of Station Rainfall in the Semiarid Seridó, Northeast Brazil. Atmospheric and Climate Sciences, n. 5, p. 408-417, 2015.

VAREJÃO-SILVA, M.A. Meteorologia e Climatologia. $2^{\text {a }}$ Edição. Brasília: INMET, 2001.

ZANELLA, M.E. Considerações sobre o clima e os recursos hídricos do semiárido nordestino. Caderno Prudentino de Geografia. Presidente Prudente, n. 36, v. Especial, p. 126142,2014

This is an Open Access article distributed under the terms of the Creative Commons Attribution Non-Commercial License which permits unrestricted non-commercial use, distribution, and reproduction in any medium provided the original work is properly cited. 